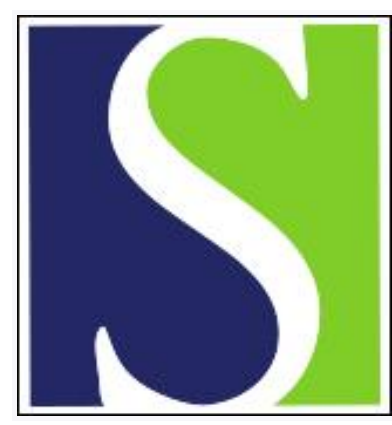

Scand J Work Environ Health 2005;31(5):336-342

https://doi.org/10.5271/sjweh.916

Issue date: Oct 2005

\title{
Stressful life events and occupational accidents
}

by Cordeiro R, Dias A

Affiliation: Department of Preventive and Social Medicine, School of Medical Science, Campinas State University-UNICAMP, Campinas SP, Brazil. cordeiro@fcm.unicamp.br

Key terms: accident proneness; distressing event; life event; occupational accident; risk factor; stress; wounds and injury epidemiology

This article in PubMed: www.ncbi.nlm.nih.gov/pubmed/16273959

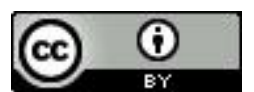




\title{
Stressful life events and occupational accidents
}

\author{
by Ricardo Cordeiro, MD, ${ }^{1}$ Adriano Dias, $\mathrm{MPH}^{2}$
}

Cordeiro R, Dias A. Stressful life events and occupational accidents. Scand J Work Environ Health 2005; 31(5):336-342.

Objective The purpose of this study was to examine the association between stressful life events and occupational accidents.

Methods This was a population-based case-control study, carried out in the city of Botucatu, in southeast Brazil. The cases consisted of 108 workers who had recently experienced occupational accidents. Each case was matched with three controls. The cases and controls answered a questionnaire about recent exposure to stressful life events.

Results Reporting of "environmental problems", "being a victim of assault", "not having enough food at home" and "nonoccupational fatigue" were found to be risk factors for work-related accidents with estimated incidence rate ratios of 1.4 [95\% confidence interval (95\% CI) 1.1-1.7], 1.3 (95\% CI 1.1-1.7), 1.3 (95\% CI 1.11.6), and 1.4 (95\% CI 1.2-1.7) respectively.

Conclusions The findings of the study suggested that nonwork variables contribute to occupational accidents, thus broadening the understanding of these phenomena, which can support new approaches to the prevention of occupational accidents.

Key terms accident proneness; distressing event; risk factor; wounds and injury epidemiology.

Occupational accidents are an important public health problem in both developing and developed countries. In contrast to what their name implies, they are not fortuitous or accidental events (1), but socially determined and preventable phenomena (2).

Some methods used to study the causes of work-related accidents focus on workers' perceptions of the occupational risks they face. Examples of these approaches are the "causal tree method" (3) and the "Italian worker model" (4). These approaches primarily address the worker's knowledge on occupational risks to which they are exposed within the factory, with little or no emphasis on the existing risks outside the work environment. However, there have been discussions about whether occupational accidents can be partially or completely caused by nonwork phenomena. In a mid-1980s prospective study of 416 air-traffic controllers from the New England area of the United States, Niemcryk et al (5) reported that nonoccupational stress was an important predictor for both occupational and nonoccupational accidents. Based on a case-control study at the beginning of the 1990s, including 8205 industrial workers from Texas, Tsai et al (1) reported an association between occupational accidents and previous nonoccupational accidents, suggesting that risk factors outside the workplace can affect both work- and nonwork-related accidents. In a 1994 case-control study in the city of Campinas, in southeast Brazil, Corrêa Filho (6) found that "health problems", "being a victim of aggression or violence", and "having sick relatives at home" were predictors of work accidents. In another case-control study conducted in 1999, in Pelotas, in south Brazil, Lima et al (7) found that "having a sick relative living at home" and "death of spouse, children, parents, or siblings" were risk factors for occupational accidents.

The study of the influence of nonwork factors on the occurrence of work-related accidents means an increase in the understanding of the causes of occupational accidents and, consequently, the broadening of the scope of preventive actions by addressing the worker in all of his or her social dimensions, beyond the limits of the workday. The purpose of this study was to investigate the

1 Department of Preventive and Social Medicine, School of Medical Science, Campinas State University-UNICAMP, Campinas SP, Brazil.

2 Department of Public Health, Botucatu Medical School, Paulista State University_UNESP, Botucatu SP, Brazil.

Reprint requests to: Dr Ricardo Cordeiro, Department of Preventive and Social Medicine, Medical Sciences School, Campinas State University-UNICAMP, Caixa Postal 6111, 13083-970 Campinas SP, Brazil. [E-mail: cordeiro@ fcm.unicamp.br] 
existence of nonwork risk factors for occupational accidents, that is, to investigate an association between phenomena not directly related to work activities and occupational accidents.

\section{Study population and methods}

This study was carried in the district area of the city of Botucatu, in southeast Brazil, a medium-sized urban area of approximately 130000 inhabitants with small agricultural production, a medium-sized industrial center (although there are some large industries), and substantial retail and service trades. We searched for nonwork risk factors of work-related accidents by carrying out a population-based case-control study, using the economically active population (EAP) of the city as the source population. The Botucatu School of Medicine Review Board approved the study proposal.

The cases were defined as city residents who reported a work-related accident in the last 90 days. They were selected by a systematic random sampling of all urban domiciles, where $94.6 \%$ of the EAP reside. The maps used for census purposes in the city urban area were used to identify the study participants. One out of four homes was systematically sampled.

The interviewers visited the selected households. When no one was at home, the visit was rescheduled for another day and a different time; if the home was found empty one more time, another visit was scheduled on a different day and at a different time; if on the third visit, the home was still unoccupied, it was excluded from the sample without replacement. The homes for which the residents refused to participate were also excluded from the study population.

An adult resident was interviewed in each visit to obtain biological, socioeconomic, and occupational data from all persons over 9 years of age living in the house. They were also asked if anyone had experienced any form of accident (related to their work, household chores, leisure, or the like) in the previous 90 days. When the answer was positive, the interviewer scheduled a new visit to interview the presumed victim. In this subsequent visit, questions were asked to confirm the occurrence of the accident and whether it had really occurred within the study period (ie, 90 days before the first visit). If these criteria were confirmed, the accident was registered, and then their connection with the occupation was checked. All of the persons who had had an occupational accident were invited to participate in the study.

For each case identified, three population controls were randomly chosen. The controls were active workers who did not report accidents in the last 90 days. They were also matched according to gender, age group (age \pm 1 year), and census city area. The identification and collection of data from the controls was continuously made throughout the sampling in the same way that each case was identified and interviewed.

Nonwork risk factors were defined as stressful events associated with occupational accidents and which did not originate from work per se or from the work environment. They were assessed using a questionnaire developed by Corrêa Filho (6), who developed, tested, used, and discussed its validation in a case-control study conducted in the city of Campinas, in southeast Brazil in 1994. The questionnaire was slightly modified for the purposes of this study. It consisted of 17 questions and was used to identify and quantify possible nonwork risk factors. The questions covered how the participants were affected by environmental problems, violence, hunger, excessive nonoccupational physical activity, difficulties at school, health problems, ill-health or death of a loved one, and problems with personal relationships. The cases were requested to answer questions about the week of the accident, and the controls about the week before the interview.

The 17 nonwork potential risk factors were as follows (with reference names in italics): (i) environmental problems in the local area (environment), (ii) pressure of authorities from third party accusations ( accusation), (iii) robbery or assault (assault), (iv) aggression or violence outside work (violence), (v) not enough food at home (hunger), (vi) excessive physical activity outside work (tiredness), (vii) difficulties with school (school), (viii) personal health problems (health), (ix) sick family member at home (family), (x) death of relative or loved one (death), (xi) birth of a child (birth), (xii) separation from child (distance), (xiii) dispute with family or friends (dispute), (xiv) getting married (marriage), (xv) marriage of close relative (child marriage), (xvi) break-up of an intimate relationship (separation), and (xvii) reconciliation of a broken intimate relationship (reconciliation).

The questionnaire was answered at home by the workers, who marked their answers by drawing a line with a pen, intercepting a horizontal straight line. The position of the mark expressed the importance ascribed to the problem addressed in the question, over the week of the accident (cases). For the controls, the reference period was the week when the interview was conducted. The answers were quantified as the distance between the beginning of the straight line on the left and its intersection with the marks made by the worker according to the method proposed by Monk (8) and Horne \& Ostberg (9). See appendix 1 for the questionnaire. Before the interview, the participant was instructed about how to answer the questions, particularly the mentioned 
no-yes scale, rehearsing with three questions on preferences related to leisure-time activities. These questions were answered in the same way as the original ones. An interviewer assisted the respondents during this process. When necessary, the interviewer explained that they could express preferences continuously by marking answers along the NO-YES line.

The case and control responses were first compared by the Wilcoxon test (10), a nonparametric procedure for testing if the responce distribution for the 17 questions was the same for both the cases and the controls.

After this initial exploration, univariate conditional logistic regression models (11) were adjusted with a matching ratio of $1: 3$, in which the dichotomous dependent variable was occupational injury (control $=0$, case $=1$ ) and the continuous independent variables were obtained from each of the above 17 questions. Finally, a multivariate conditional logistic regression model (11) was adjusted with a matching ratio of $1: 3$, for which the dichotomous dependent variable corresponded to the occurrence of the accident (control $=0$, case $=1$ ) and the continuous independent variables corresponded to the values from the questionnaire, which provided an estimative for the incidence rate ratio of $\mathrm{P} \leq 0.25$ in the univariate models (12), as well as the covariates "years of schooling", "occupation", and "length of time in the occupation". Occupation was classified using the main groups of the Brazilian Occupation Classification Index (13), which is comparable to the International Standard Classification of Occupations (14). The backward method was used for modeling, using as a P-value of $<0.05$ as the criterion to retain variables (11). The characterization of the variables as nonoccupational risks was

Table 1. Distribution of accidents by gender and age among the cases in a case-control study in southeast Brazil in 2002. (AF = absolute frequency, $\mathrm{RF}$ = reletive frequency)

\begin{tabular}{|c|c|c|c|c|c|c|c|}
\hline \multirow[t]{3}{*}{ Age group } & \multicolumn{4}{|c|}{ Gender } & \multirow{2}{*}{\multicolumn{3}{|c|}{ Total }} \\
\hline & \multicolumn{2}{|c|}{ Female } & \multicolumn{2}{|c|}{ Male } & & & \\
\hline & $A F$ & $\begin{array}{c}\mathrm{RF} \\
(\%)\end{array}$ & $\mathrm{AF}$ & $\begin{array}{c}\mathrm{RF} \\
(\%)\end{array}$ & $\mathrm{AF}$ & $\begin{array}{c}\mathrm{RF} \\
(\%)\end{array}$ & $\begin{array}{c}\text { Accumu- } \\
\text { lative- } \\
\text { RF }(\%)\end{array}$ \\
\hline 16 years & 0 & 0.0 & 1 & 0.9 & 1 & 0.9 & 0.9 \\
\hline 17 years & 0 & 0.0 & 1 & 0.9 & 1 & 0.9 & 1.8 \\
\hline 18 years & 0 & 0.0 & 1 & 0.9 & 1 & 0.9 & 2.8 \\
\hline 19 years & 0 & 0.0 & 2 & 1.8 & 2 & 1.8 & 4.6 \\
\hline 20 years & 0 & 0.0 & 3 & 2.8 & 3 & 2.8 & 7.3 \\
\hline 21-30 years & 5 & 4.6 & 24 & 22.0 & 29 & 26.6 & 33.9 \\
\hline $31-40$ years & 6 & 5.5 & 33 & 30.3 & 39 & 35.8 & 69.7 \\
\hline $41-50$ years & 8 & 7.3 & 12 & 11.0 & 20 & 18.3 & 88.1 \\
\hline $51-60$ years & 2 & 1.8 & 9 & 8.3 & 11 & 10.1 & 98.2 \\
\hline $61-70$ years & 1 & 0.9 & 0 & 0.0 & 1 & 0.9 & 99.1 \\
\hline $71-80$ years & 0 & 0.0 & 1 & 0.9 & 1 & 0.9 & 100.0 \\
\hline Total & 22 & 20.2 & 87 & 79.8 & 109 & 100.0 & \\
\hline
\end{tabular}

done through odds ratio estimates from the multivariate adjustment, which coincided with the rate ratio incidence in the study design used (15).

The selection of the participants was made after the visits to the homes between 16 May 2002 and 15 September 2002, using all 195 census urban areas in Botucatu. Initially, all the domiciles were listed, from which 10311 were sampled. Of these, 650 (6.3\%) were found unoccupied on three consecutive visits and were excluded from the sample without replacement. In 33 homes $(0.3 \%)$, the adult resident refused to participate, and they were also excluded from the sample without replacement. Thus the studied sample consisted of 9626 domicile residents.

\section{Results}

During the study, 198 nonfatal accidents were reported as having occurred in the 90 days prior to the home interviews. Of them, 109 were classified as occupational accidents, 94 (86.2\%) were typical, and 15 (13.8\%) occurred during commuting. The remaining 89 cases were classified as nonoccupational, such as those occurring as a consequence of traffic or domestic accidents or another type of accident. Table 1 shows the gender of the cases and their age distribution, highlighting that one out of three accidents affected young adults up to 30 years of age, with $7.4 \%$ of the victims being 20 years of age or less.

Most accidents consisted of cuts, contusions, fractures, or severe lacerations, mainly on the hands or upper limbs, head (except eyes), and lower limbs (except feet). The prevailing immediate causes were related to machines and equipment, falls, car accidents, and falling objects. Most of the occupational accidents were of light-to-moderate severity, 99 (90.8\%) being responsible for absences from work of up to 15 days.

Of the 109 cases, $108(99.1 \%)$ agreed to participate in the study and completed the questionnaire on nonwork risks (appendix 1). One case refused to participate.

With the 108 victims, 324 nonaccident controls were matched, according to the aforementioned criteria; altogether 432 workers were studied.

The hypothesis of an equal distribution for each of the 17 nonwork risk factors under study across the cases and controls was rejected using the Wilcoxon test, with a significance of 0.05 . Table 2 shows the mean values for the cases and controls, and the results of this test.

Using univariate logistic models, we observed that environmental, accusation, assault, violence, hunger, tiredness, schooling, health, death, birth, distance, dispute, separation, and reconciliation corresponded to 
Table 2. Mean values of the case and control responses, observed $z$ statistic and associated P-values obtained by the use of bicaudal Wilcoxon rank-sum tests for comparison of the case and control responses in a case-control study in southeast Brazil in 2002. A low value approaches NO and a high value approaches YES. $\left(z_{\text {obs }}=\right.$ observed $z$ statistic $)$

\begin{tabular}{lrlrr}
\hline Variable & \multicolumn{2}{c}{ Mean (cm) } & \multirow{2}{*}{$Z_{\text {obs }}$} & P-value \\
\cline { 2 - 3 } & Cases & Controls & & \\
\cline { 2 - 4 } Environment (question 1) & 0.616 & 0.079 & 6.06 & $<0.0001$ \\
Accusation (question 2) & 0.749 & 0.090 & 6.52 & $<0.0001$ \\
Assault (question 3) & 0.638 & 0.034 & 6.83 & $<0.0001$ \\
Violence (question 4) & 0.271 & 0.051 & 5.81 & $<0.0001$ \\
Hunger (question 5) & 0.650 & 0.069 & 7.63 & $<0.0001$ \\
Tiredness (question 6) & 1.140 & 0.276 & 6.70 & $<0.0001$ \\
School (question 7) & 0.357 & 0.170 & 4.74 & $<0.0001$ \\
Health (question 8) & 1.132 & 0.791 & 4.10 & $<0.0001$ \\
Family (question 9) & 0.781 & 0.787 & 3.07 & 0.0021 \\
Death (question 10) & 0.544 & 0.167 & 5.74 & $<0.0001$ \\
Birth (question 11) & 0.291 & 0.069 & 7.18 & $<0.0001$ \\
Distance (question 12) & 0.248 & 0.036 & 5.81 & $<0.0001$ \\
Dispute (question 13) & 0.587 & 0.340 & 5.98 & $<0.0001$ \\
Marriage (question 14) & 0.163 & 0.140 & 5.50 & $<0.0001$ \\
Child marriage (question 15) & 0.036 & 0.036 & 5.52 & $<0.0001$ \\
Separation (question 16) & 0.487 & 0.987 & 2.24 & 0.0253 \\
Reconciliation (question 17) & 0.147 & 0.834 & 2.05 & 0.0402 \\
\hline & & & & \\
\hline
\end{tabular}

P-values below 0.25 . Table 3 shows the statistics from these adjustments.

Adjusting the preceding multivariate logistic model, we observed that environment, assault, hunger, and tiredness were work-accident risk factors, with estimated incidence rate ratios of 1.4 [95\% confidence interval (95\% CI) 1.1-1.7], 1.3 (95\% CI 1.1-1.7), 1.3 (95\% CI 1.1-1.6), and 1.4 (95\% CI 1.2-1.7), respectively, per centimeter marked for each question. In addition, years of schooling was a protection factor, with an estimated incidence rate ratio of 0.9 (95\% CI 0.9-1.0). Table 4 shows the statistics from the model adjustments. The estimates for the other variables produced P-values greater than 0.05 and were discarded. We did not observe any statistically significant interaction term between the selected variables $(\alpha=0.05)$. The analysis of the adjusted model residuals did not identify any violations of the logistic model assumptions.

\section{Discussion}

The probability of experiencing an occupational accident is not homogeneously distributed between workers performing different tasks in distinct occupations. The level of exposure to risks differentiates tasks and occupations. The objective of this study was to investigate the association between nonoccupational risks and work-related accidents. The cases and controls were
Table 3. Estimated $\beta$ parameters, P-values, and incidence rate ratios obtained by the adjustment of the univariate logistic models investigating nonwork risks for occupational accidents in a case-control study in southeast Brazil in 2002.

\begin{tabular}{lccc}
\hline Variable & $\begin{array}{c}\text { Estimated a } \\
\beta \\
\text { parameter }\end{array}$ & P-value & $\begin{array}{c}\text { Estimated } \\
\text { incidence } \\
\text { rate ratio }\end{array}$ \\
\hline Environment (question 1) & 0.2359 & 0.0047 & 1.266 \\
Accusation (question 2) & 0.2320 & 0.0019 & 1.261 \\
Assault (question 3) & 0.2880 & 0.0080 & 1.334 \\
Violence (question 4) & 0.1857 & 0.0828 & 1.204 \\
Hunger (question 5) & 0.2629 & 0.0036 & 1.301 \\
Tiredness (question 6) & 0.2156 & 0.0004 & 1.241 \\
School (question 7) & 0.1139 & 0.1836 & 1.121 \\
Health (question 8) & 0.0480 & 0.2366 & 1.049 \\
Family (question 9) & -0.0011 & 0.9797 & 0.999 \\
Death (question 10) & 0.1140 & 0.0525 & 1.121 \\
Birth (question 11) & 0.1556 & 0.0910 & 1.168 \\
Distance (question 12) & 0.2093 & 0.0914 & 1.233 \\
Dispute (question 13) & 0.0634 & 0.2351 & 1.069 \\
Marriage (question 14) & 0.0205 & 0.8350 & 1.021 \\
Child marriage (question 15) & -0.0011 & 0.9959 & 0.999 \\
Separation (question 16) & -0.0802 & 0.1090 & 0.923 \\
Reconciliation (question 17) & -0.1746 & 0.0348 & 0.840 \\
\hline
\end{tabular}

${ }^{a}$ Refers to a centimeter difference in line length.

Table 4. Estimated $\beta$ parameter, $\mathrm{P}$-value, incidence rate ratio, and $95 \%$ confidence interval $(95 \% \mathrm{Cl})$ obtained by adjusting a the multivariate logistic model investigating nonwork risks for occupational accidents in a case-control study in southeast Brazil in 2002.

\begin{tabular}{lrrrr}
\hline Variable & $\begin{array}{c}\text { Esti- } \\
\text { mated } \\
\beta\end{array}$ & $\begin{array}{r}\text { P-value } \\
\text { para- } \\
\text { meter }\end{array}$ & $\begin{array}{c}\text { Estimat- } \\
\text { ed inci- } \\
\text { dence } \\
\text { rate } \\
\text { ratio }\end{array}$ & $\begin{array}{c}\text { 95\% } \\
\text { bl for } \\
\text { estimate } \\
\text { of inci- } \\
\text { dence rate } \\
\text { ratio }\end{array}$ \\
\hline Environment (question 1) & 0.3207 & 0.0057 & 1.378 & $1.098-1.730$ \\
Assault (question 3) & 0.2955 & 0.0120 & 1.344 & $1.067-1.692$ \\
Hunger (question 5) & 0.2643 & 0.0088 & 1.302 & $1.069-1.587$ \\
Tiredness (question 6) & 0.3464 & $<0.0001$ & 1.414 & $1.207-1.656$ \\
Years of schooling & -0.802 & 0.0256 & 0.923 & $0.860-0.990$
\end{tabular}

${ }^{a} \chi^{2}$ likelihood ratio $=67.218,5$ degrees of freedom, $P<0.0001$.

b Refers to a centimeter difference in line length for environment,

assault, hunger, and tiredness and to a year's difference for schooling.

matched according to gender, age group, and census urban areas to enhance the comparability of the cases and controls concerning exposure to occupational risks, given that the census urban areas were relatively small and located in contiguous areas. They consisted of approximately 200 domiciles each and can be considered a reasonably homogeneous region from a social point of view. In addition, in the multivariate logistic analysis, the estimate for risks was controlled for the main occupational groups, length of time in the occupation, and completed years of schooling, also as a strategy to control possible confounding of the occupations. Such confounding could happen, given that the tasks for which there was intense exposure to occupational risks were more commonly 
performed by workers with a lower socioeconomic level, living in poor urbanized areas, and more exposed to nonwork-related stress factors.

A limitation of this study was the use of a case-control design to obtain the data. The data were obtained, for the cases, after a work accident. Theoretically this occurrence could have distorted the perception of the cases with respect to the events that occurred close to the time of the accident. To minimize this possibility, the cases were identified from the characterization of any type of accident (without prior mention of being work-related), and they answered a questionnaire about strictly nonoccupational events (without any mention of work factors), covering environmental, social, and personal problems (see appendix 1). We decided in favor of a case-control design due to the rarity of the event under study. In the city of Botucatu, the incidence proportion of occupational accidents is 0.015 per year (16). Workers were asked about the experience of accidents only in the previous 3 months to minimize the possibility of recall bias (17). Therefore, the proportion of occupational accidents in 3 months was estimated at 0.0038 ; this figure would have made it extremely difficult to conduct a cohort study that produced enough accidents for the analysis. The low number of occupational accidents is a strong argument that has been forcing many epidemiologists to opt for the use of case-control designs in studying the relationships between exposures and occupational accidents. As stated by Swaen et al (18), one of the most important methodological constraints in research aimed at investigating risk factors for occupational accidents is that, in most studies, data on risk factors are collected after the occurrence of the accident. In theory, a possible consequence of a casecontrol design in this context would be a biased deviation from the null hypothesis. Such a situation could occur if cases tend to blame themselves for having experienced the occupational accident and found quick explanations for why they had risky behavior. However, even though such a situation occurred in this study, one still could ask why, from 17 different nonwork related stressful events, the workers chose the particular four risks mentioned.

The Wilcoxon rank-sum test was used as a nonparametric method to test if the distribution of answers for the cases and controls was similar. This was an initial univariate exploration, which did not consider possible confounding factors and interactions between the variables, investigating differences in answering standards from the cases and controls. As a preliminary test, we observed that the 17 nonwork variables were differently distributed between the cases and controls.

The backward variable selection method was used in the multivariate logistic adjustment due to the lack of a prior explanatory model. With the use of this method, according to table 4, environment, assault, hunger, and tiredness were identified as risks for work-related accidents. All of these estimates were controlled for gender, age group, domicile census track (due to matching), years of schooling, occupation, and length of time in the occupation (due to the analysis).

On the assumption that the results could be generalized, it is plausible to think that to experience environmental problems, to be a victim of assault, to experience hunger, and to suffer from tiredness are factors that interfere negatively with the performance of daily work activities, increasing the chances of experiencing occupational accidents. According to the adjusted model results, each centimeter marked in the questions related to the variables corresponded to a $30 \%$ to $40 \%$ increase in the risk of experiencing a work-related accident.

Many studies have highlighted the association between tiredness and occupational accidents (18-26), suggesting that, among other things, tiredness compromises the capacity of the nervous system to efficiently regulate a person's balance, as well as increase the defensive response time to external dangers. Swaen et al (27), in a recent study of more than 12000 workers, found an incidence rate ratio of 1.7 (95\% CI 1.0-2.8) for occupational accidents between workers who described themselves as tired against those who were not tired. Macdonald et al (28), in the study of 882 adults in Ontario, Canada, in 1998, reported that not only sleeping problems, but also financial problems and the need for counseling could be predictors of work, domestic, and leisure-time accidents.

We found no references in the literature about associations between environmental problems (environment), being a victim of assault (assault), or not having enough food at home (hunger) and work-related accidents. A plausible hypothesis for these associations could be a possible attention difficulty in the execution of worktasks by workers who had been influenced by external aggression.

These findings, which suggest that variables outside the work environment contribute to the genesis of occupational accidents, increase the understanding of the causes of these phenomena, and widen the perspective on new approaches to the prevention of occupational accidents, traditionally focused on the control of occupational risks. If variables outside the work environment are co-responsible for the experience of work-related accidents, efforts to prevent them have to also address the risks situated beyond the workplace. As a corollary, the efficiency of industrial hygiene, defined as the science of anticipating, recognizing, evaluating, and controlling workplace conditions that may cause workers' injury or illness (29), is limited. Thus policies towards the improvement of the work environment and relationships are not enough per se to assure an acceptable decrease 
in occupational accident rates. Public health professionals, managers, politicians, and the workers themselves should take this into account when planning policies to prevent occupational accidents.

\section{Acknowledgments}

The authors would like to thank the State of São Paulo Research Foundation for financing this study (file FAPESP 00/09105-0).

\section{References}

1. Tsai SP, Bernacki EJ, Dowd CM. The relationship between work-related and non-work-related injuries. J Community Health 1991;16(4):205-12.

2. Dwyer T. Life and death at work. Industrial accidents as a case of socially produced error. New York (NY): Plenum Press; 1991.

3. Monteau M. A practical method of investigating accident factors: principles and experimental applications. Luxembourg: Commission of the European Communities, directorate-general "scientific and technical information and information management"; 1977.

4. Oddone I, Marri G, Gloria S. L'ambienti di lavoro-la fabbrica nel territorio. [Work environment- the factory in the site]. Rome: Editrice Sindicale Italiana; 1967.

5. Niemcryk SJ, Jenkins CD, Rose RM, Hurst MW. The prospective impact of psychosocial variables on rates of illness and injury in professional employees. J Occup Med 1987;29(8):645-2.

6. Corrêa Filho HR. Percepção de riscos na ocupação precedendo lesões do trabalho: um estudo no município de Campinas, São Paulo, 1992-1993 [Perception of risk factors in work accidents analysis: a study in an industrial developed city in a south-eastern state in Brazil, 1992-1993][dissertation]. São Paulo: School of Public Health, University of São Paulo; 1994.

7. Lima RC, Victora CG, Dall'Agnol M, Facchini LA, Fassa AG. Associação entre as características individuais e sócioeconômicas e os acidentes do trabalho em Pelotas, Rio Grande do Sul, Brasil [Association between individual and socioeconomic characteristics and work-related accidents in Pelotas, Southern Brazil]. Cad Saude Publica 1999;15(3):569-80.

8. Monk TH. A visual analogue scale technique to measure global vigor and affect. Psychiatry Res 1989; 27(1):89-99.

9. Horne JA, Ostberg O. A self-assessment questionnaire to determine morningness-eveningness in human circadian rhythms. Int J Chronobiol 1976;4(2):97-110.

10. Snedecor GW, Cochran WG. Statistical methods. Ames (IA): The Iowa State University Press; 1980.

11. Hosmer Jr DW, Lemeshow S. Applied logistic regression. 2nd ed. New York (NY): John Wiley \& Sons; 2000.

12. Rothman KJ, Greenland S. Modern epidemiology. 2nd ed.
Philadelphia (PA): Lippincott-Raven; 1998.

13. Classificação Brasileira de Ocupações [Brazilian Occupation Classification Index.] [homepage on the Internet]. Brasília: Ministry of Labour; [updated 2004 Nov 8; cited 2005 May 2]. Available from: http://www.mtecbo.gov.br/index.htm.

14. International Labour Office (ILO). International standard classification of occupations. Geneva: ILO; 1981.

15. Pearce N. What does the odds ratio estimate in a case-control study? Int J Epidemiol 1993;22:1189-92.

16. Cordeiro R, Sakate MA, Clemente APG, Diniz CS, Donalisio MR. Subnotificação de acidentes do trabalho não fatais em São Paulo, 2002 [Underreport of non fatal work related injury in Botucatu, southeast Brazil, 2002]. Rev Saude Publica 2005;39(3). In press.

17. Solomon C. Accidental injuries in agriculture in the UK. Occup Med 2002;2(8):461-6.

18. Swaen GM, van Amelsvoort LP, Bültmann U, Slangen JJ, Kant IJ. Psychosocial work characteristics as risk factors for being injured in an occupational accident. J Occup Environ Med 2004;46:521-7.

19. Hsiao H, Simeonov P. Preventing falls from roofs: a critical review. Ergonomics 2001;44(5):537-61.

20. Åkerstedt T, Fredlund P, Gillberg M, Jansson B. A prospective study of fatal occupational accidents-relationship to sleeping difficulties and occupational factors. J Sleep Res 2002;11:69-71.

21. Carter N, Ulfberg J, Nyström B, Edling C. Sleep debt, sleepiness and accidents among males in the general population and male professional drivers. Accid Anal Prev 2003;35:613-7.

22. Leger D. The cost of sleep-related accidents: a report for the National Commission on Sleep Disorders Research. Sleep 1994;17:84-93.

23. Ulfberg J, Carter N, Edling C. Sleep-disordered breathing and occupational accidents. Scand J Work Environ Health 2000;26:237-42.

24. Lindberg E, Carter N, Gislason T, Janson C. Role of snoring and daytime sleepiness in occupational accidents. Am J Respir Crit Care Med 2001;164:2031-5.

25. Johnston RB, Howard ME, Cawley PW, Losse GM. Effect of lower extremity muscular fatigue on motor control performance. Med Sci Sports Exerc 1998;30(12):1703-7.

26. Sparto PJ, Parnianpour M, Reinsel TE, Simons S. The effect of fatigue on multijoint kinematics, coordination, and postural stability during a repetitive lifting test. J Orthop Sports Phys Ther 1997;25(1):3-12.

27. Swaen GMH, von Amelsvoort LGPM, Bültmann U, Kant IJ. Fatigue as a risk factor for being injured in an occupational accident: results from the Maastricht Cohort Study. Occup Environ Med 2003;60 suppl I:i88-i92.

28. Macdonald S, Wells S, Lothian S. Comparison of lifestyle and substance use factors related to accidental injuries at work, home and recreational events. Accid Anal Prev 1998;30(1):21-7.

29. Occupational Safety and Health Administration (OSHA). Industrial Hygiene. Washington (DC): United States Department of Labor. OSHA 31431998 (revised) [updated 2005 Apr 28; cited 2005 May 5]. Available from: http:// www.osha.gov/Publications/OSHA3143/OSHA3143.htm.

Received for publication: 14 February 2005 


\section{Appendix 1}

\section{Contents of questionnaire used in the study}

\section{Title}

What is the importance of each of the following situations in your personal life in the WEEK OF THE ACCIDENT / LAST WEEK?

\section{Instructions}

Mark the point on the line that indicates the importance of the question for you. If there is absolutely no importance for you, mark a vertical line on the left, at the beginning of the horizontal line. If it is totally important for you, mark a vertical line on the right at the end of the horizontal line. If it is of some importance, mark a vertical line on the horizontal line corresponding to its importance for you.

\section{List of questions}

1) Have you felt your work has suffered because you have had some environmental problem at home, in your street, or local area? (For example: flooding, roof problem, collapsed wall, fire, leak, pollution, etc).

2) Have you felt your work has suffered because you have been under pressure from the police or authorities because of accusations from third parties?

3) Have you felt your work has suffered because you have been the victim of an assault or robbery?

4) Have you felt your work has suffered because you have been the victim of aggression or violence outside of work?

5) Have you felt your work has suffered because of lack of food at home?

6) Have you felt your work has suffered because you have had a lot of physical activity outside of work? (For example: working on the house, repairing the car, gardening, sport, moving house, etc)

7) Have you felt your work has suffered because you have had difficulties at school?

8) Have you felt your work has suffered because you have had a health problem?

9) Have you felt your work has suffered because there is member of the family ill at home?

10) Have you felt your work has suffered because of a death of a relative or loved one?

11) Have you felt your work has suffered because you have or will have a child?

12) Have you felt your work has suffered because your son or daughter is leaving home?

13) Have you felt your work has suffered because you have had a dispute with a close relative or loved one?

14) Have you felt your work has suffered because you have just married or will soon marry?

15) Have you felt your work has suffered because a close relative or loved one has just married or will soon marry?

16) Have you felt your work has suffered because you have had a dispute or have separated from your boy- or girlfriend, fiancé, spouse, or partner?

17) Have you felt your work has suffered because you have reconciled with (made peace with) your boy- or girlfriend, fiancé, spouse, or partner?

\section{Scale used for each question}

